\title{
Migrant contract workers and occupational accidents in the furniture industry.
}

\begin{abstract}
Studies on the rate of occupational accidents among migrant contract workers is sparse, although they are increasingly used in the furniture manufacturing industry in Malaysia. Therefore, the rate of occupational accidents among migrant contract workers in the Malaysian wooden furniture industry were studied in sixty furniture manufacturing factories, using a structured questionnaire. The two-part questionnaire were aimed at collecting data on comparative accidents rates among the foreign workers and local workers, while identifying the main factors that lead to occupational accidents. The findings of the study show conclusively that the migrant contract workers are less prone to occupational accidents compared to their local counterparts and hence, are more productive. Further, the results also revealed that the migrant contract workers have a more positive attitude towards the work and hence, pick up the essentials of safe working quickly. It must therefore be recognized that the production oriented mentality prevalent in the industry which has been argued to compromise occupational safety and health standards in the industry may be debatable. In this context, it is essential for the policy makers to re-examine the employment of migrant contract workers for the furniture manufacturing industry, as changing the psycho-economic parameters of the industry may be warranted before the industry is deemed attractive to the local workforce.
\end{abstract}

Keyword: Foreign workers; Occupational accidents; Labour intensive; Policy. 